\title{
Distinct Tribological Mechanisms of Various Oxide Nanoparticles Added in PEEK \\ Composite Reinforced with Carbon Fibers
}

\author{
Lihe Guo ${ }^{\mathrm{a}, \mathrm{b}}$, Huimin $\mathrm{Q}^{\mathrm{a}}{ }^{\mathrm{a}, \mathrm{b}}$, Ga Zhang ${ }^{\mathrm{a},{ }^{*}}$, Tingmei Wang ${ }^{\mathrm{a}}$, Qihua Wang ${ }^{\mathrm{a}}$ \\ ${ }^{a}$ State Key Laboratory of Solid Lubrication, Lanzhou Institute of Chemical Physics, Chinese \\ Academy of Sciences, Lanzhou 730000, China \\ ${ }^{\mathrm{b}}$ University of Chinese Academy of Sciences, Beijing 100049, China \\ * Corresponding author: Prof. Ga Zhang \\ E-mail: gzhang@licp.cas.cn. \\ Tel: +86-931-4968041. \\ Fax: +869314968180
}

\begin{abstract}
The tribological behaviors of various oxide nanoparticles, i.e. $\mathrm{Bi}_{2} \mathrm{O}_{3}, \mathrm{CuO}, \mathrm{SiO}_{2}$ and $\mathrm{ZrO}_{2}$, added into a carbon fibers reinforced polyether-ether-ketone were comprehensively investigated. It was demonstrated that nanoparticle types played an important role in the tribological performance. When sliding took place at a low FV (load $\times$ speed) condition, the addition of $\mathrm{CuO}$ and $\mathrm{ZrO}_{2}$ nanoparticles led to the formation of patch-like tribofilms increasing friction and wear. However, at FV factors ranging from 30 to $300 \mathrm{~N} \cdot \mathrm{m} / \mathrm{s}$, the hard nanoparticles, i.e. $\mathrm{SiO}_{2}$ and $\mathrm{ZrO}_{2}$, resulted in dramatic improvement of the tribological properties. Moreover, nano- $\mathrm{ZrO}_{2}$ was significantly more effective than nano- $\mathrm{SiO}_{2}$ for enhancing the tribological performance. Hard nanoparticles released onto the sliding interface removed the tribo-oxidation layer on steel counterface. Hereafter, they were "tribo-sintered" into an oxide-based tribofilm having a high load-carrying capability. However, the soft nanoparticles, i.e. $\mathrm{Bi}_{2} \mathrm{O}_{3}$ and $\mathrm{CuO}$, did not help to form a robust and lubricating tribofilm.
\end{abstract}


Keywords: PEEK composite; Oxide nanoparticles; Hardness; Tribofilm 


\section{Introduction}

It has been identified by numerous works that tribofilm formation is one of the most important factors influencing the tribological performance of polymeric tribo-materials. Complex tribo-physical and chemical reactions can take place on the friction interface when neat polymer [1-3] and polymer composites [4, 5] rub with a metallic counterpart, and thereby result in the formation of tribofilms as a third-body layer. In general, a thin and homogeneous tribofilm can separate or at least mitigate the direct rubbing between the sliding pairs, and hence leads to a high tribological performance $[6,7]$.

It has been commonly recognized that the addition of solid lubricants, e.g. polytetrafluoroethylene (PTFE), graphite, $\mathrm{MoS}_{2}$, into polymer matrix leads to the formation of a solid lubricant tribofilm owing to their layered structures [8]. Moreover, Xue et al. [9] and Gao [3] disclosed that breakage of molecule chains of PTFE occurred and thereafter the active radicals chelated with counterpart steel, which was believed important in regard of tribofilm formation. In particular, the combination of reinforcing fillers, e.g. carbon, glass and aramid fibers, and solid lubricants generates a synergetic role in enhancing the tribological performance of polymers [10, 23]. The reinforcing fibers improve the load-carrying capacity of polymer matrix; whereas the solid lubricants apt to transfer to the metal counterpart.

Since the last decades, tribological behaviors of polymer nanocomposites have attracted great attention. It has been demonstrated that the addition of various nanoparticles, e.g. $\mathrm{ZrO}_{2}, \mathrm{Al}_{2} \mathrm{O}_{3}, \mathrm{SiC}, \mathrm{Cu}, \mathrm{SiO}_{2}$, into polymer matrix, e.g. 
polyether-ether-ketone

(PEEK)

PTFE,

polyformaldehyde

(POM), ultra-high-molecular-weight polyethylene (UHMWPE), significantly enhances the tribological performance [6, 11-15]. Bahadur et al. [16] reported that the inclusion of $\mathrm{TiO}_{2}, \mathrm{CuO}$ nanoparticles improved the tribological performance of polyphenylene sulfite (PPS); whereas the addition of $\mathrm{ZnO}, \mathrm{SiC}$ nanoparticles led to a negative role. $\mathrm{In}$ most of these previous works, the enhanced tribological performance was ascribed to the formation of a "high quality" tribofilm with improved cohesion property [17] and interface adhesion [11]. Recent work of Hurris et al. [18] manifested that radicals derived from broken PTFE chains chelated with both $\mathrm{Al}_{2} \mathrm{O}_{3}$ nanoparticles and the steel counterpart, which was suspected essential for the high tribological performance of the PTFE/nano- $\mathrm{Al}_{2} \mathrm{O}_{3}$ nanocomposites. Moreover, the addition of nanoparticles enhances simultaneously the stiffness and toughness of polymer matrices, and thus prevents crack propagation in the polymer matrices when being rubbed $[6,14,19]$.

It has been demonstrated in the last decade that further addition of ceramic nanoparticles, e.g. $\mathrm{SiO}_{2}$ and $\mathrm{TiO}_{2}$, into conventional polymer composites reinforced with short carbon fibers (SCF) obviously enhanced the tribological performance $[10,20$, 21]. The combination of nanoparticles and the conventional fillers provided a potential formulation route of high-performance tribo-composites [22]. With respect to the tribological mechanisms of the nanoparticles, several explanations exist. Nanoparticles can protect fibers from being severely destroyed, e.g. breakage, debonding and peeling off [23], by homogenizing the stress in the area between the fibers. Moreover, rolling of 
nanoparticles on the interface can reduce the friction and wear $[24,25,26]$. Our recent works [27] revealed that a silica-based tribofilm was formed when silica/SCF/epoxy (EP) was rubbed with a steel counterpart. It was suspected that release of nanoparticles, mixing of wear products and tribo-sintering of nanoparticles dominated the formation of the glassy tribofilm $[27,28]$.

Although the enhanced tribological performance by adding nanoparticles into conventional composites has been identified by various works [8, 20, 25], explanations on the tribological mechanisms do not reach an agreement yet. The impact of physical and chemical properties of the nanoparticles on the tribological behaviors has not been comprehensively understood. Kato et al. [29] inserted various metal oxide nanoparticles onto a metal-metal sliding interface. The authors disclosed that the tribofilm structures were closely dependent on the melting points of the oxides (or in terms of oxygen diffusion rates), which exerted an important role in tribo-sintering actions. It is therefore expected that comprehensive investigations on the impact of nanoparticle types can gain insight into tribological mechanisms of the nanoparticles added in polymer hybrid nanocomposites.

PEEK as a high-performance thermoplastic is being increasingly employed in various fields for its unique advantages, such as high strength, high modulus, good thermal stability, chemical inertness and abrasion resistance [30]. In the present work, four kinds of oxide nanoparticles with distinct hardness and melting point, i.e. $\mathrm{Bi}_{2} \mathrm{O}_{3}, \mathrm{CuO}, \mathrm{SiO}_{2}$ and $\mathrm{ZrO}_{2}$, were added into a SCF-reinforced PEEK composite. The effect of 
nanoparticle types on the tribological behavior of the composite was comprehensively investigated in a wide range of loading conditions. In particular, the nanostructures of the tribofilms were characterized in-depth. It is the aim of this work to reveal the impact of nanoparticles' properties on the tribological behaviors and tribofilm structures of the hybrid PEEK composites. It is also the goal of this work to gain deeper insight into the tribological mechanisms of the nanoparticles.

\section{Experimental details}

\subsection{Materials preparation}

The composites prepared in this study were based on PEEK powders having an average diameter of $50 \mu \mathrm{m}(450 \mathrm{PF}$, Victrex, UK). SCF (Nantong Senyou Carbon Fiber Co., Ltd., China) were added into PEEK matrix as reinforcing fillers. The diameter of SCF was $7 \mu \mathrm{m}$ and the length-diameter ratio was in the range of 1:5-1:10. Friedrich et al. $[31,32]$ has conducted comprehensive studies on the effect of SCF content on tribological properties of PEEK; it was demonstrated that PEEK exhibited the best wear resistance with the addition of $10 \mathrm{vol} \% \mathrm{SCF}$. In the present work, the conventional PEEK composite filled with 10 vol\% SCF served as reference sample. Four kinds of oxide nanoparticles, i.e. $\mathrm{Bi}_{2} \mathrm{O}_{3}, \mathrm{CuO}, \mathrm{SiO}_{2}$ and $\mathrm{ZrO}_{2}$, were added into SCF-reinforced PEEK, respectively. The nano- $\mathrm{Bi}_{2} \mathrm{O}_{3}$ was supplied by Alfa Aesar (China) and the other three nanoparticles were supplied by Beijing DK Nano Technology Co., Ltd. (China). The morphologies of the nanoparticles are given in Fig. 1 and their diameters (following 
manufacturers' specifications) are illustrated in Tab. 1. As listed in Tab.1, the nanoparticles studied exhibit distinctly different hardness and melting points. It was manifested in our previous works $[27,33]$ that the addition of 1 vol\% $\mathrm{SiO}_{2}$ nanoparticles enhanced dramatically the tribological performance of SCF reinforced PEEK and EP. Although the content of nanoparticles affected the running-in duration, further increment of nano-SiO $\mathrm{S}_{2}$ fraction did not influence significantly the friction and wear in steady friction stage [27]. With such a context, the volume fraction of oxide nanoparticles in the hybrid nanocomposite was fixed in the present work at $1 \mathrm{vol} \%$. The hybrid nanocomposites and the reference sample are designated as $\mathrm{Bi}_{2} \mathrm{O}_{3} / \mathrm{SCF} / \mathrm{PEEK}$, $\mathrm{CuO} / \mathrm{SCF} / \mathrm{PEEK}, \mathrm{SiO}_{2} / \mathrm{SCF} / \mathrm{PEEK}, \mathrm{ZrO}_{2} / \mathrm{SCF} / \mathrm{PEEK}$ and SCF/PEEK, respectively.

The SCF were ultrasonically cleaned in acetone for $0.5 \mathrm{~h}$ and then dried in air before use. The PEEK powders, SCF and nanoparticles were mixed and rigorously stirred in a high-speed stirrer. Afterwards, the mixtures were compressed and heated up to $375{ }^{\circ} \mathrm{C}$ in a steel mold. The compression pressure was kept at $8 \mathrm{MPa}$ for $60 \mathrm{~min}$ to allow full compression sintering. Finally, the samples were cooled naturally in the mold. The samples for tribological tests were machined from the compressed plates with desired dimensions.

\subsection{Tribological test procedure}

The friction and wear behaviors of the PEEK composites were studied with Plate-On-Ring (POR) tests on a MRH-3 test rig (Jinan Yihua Testing Machine, China). 
The contact configuration of the sliding pair was illustrated schematically in Fig. 2. The specimens for friction tests were plates with a dimension of $12.32 \mathrm{~mm} \times 12.32 \mathrm{~mm} \times$ $19.05 \mathrm{~mm}$. Standard bearing steel rings (GCr15, GB/T 18254-2002) were utilized as counterpart and the diameter of the steel ring was $49.22 \mathrm{~mm}$. The counterpart ring was finished by mechanical grinding using abrasive papers and its roughness $R_{a}$ was controlled at about $0.27 \mu \mathrm{m}$. Sliding tribological tests were conducted in air at room temperature under various loading conditions, i.e. FV (force $\times$ speed) values were 6,30 , $100,150,200,300 \mathrm{~N} \cdot \mathrm{m} / \mathrm{s}$. Each test lasted $5 \mathrm{~h}$, which was enough to ensure steady friction for all samples. Each test was repeated for at least three times to calculate the average friction coefficient and wear rate. Both the polymer specimens and counterparts were thoroughly cleaned before tribological tests.

\subsection{Worn surface and tribofilm analysis}

The worn surfaces of the PEEK composites and the steel counterpart were inspected using an optical microscope (Axio Imager A2m, Zeiss) and Field Emission Scanning Electron Microscope (FE-SEM, Mira3, Tescan). Prior to SEM inspections, the samples were coated with a thin layer of gold for enhancing the electrical conductivity. The accelerating voltages were 5 and $15 \mathrm{kV}$ for inspecting the polymer surface and steel counterface, respectively. The elemental compositions of the tribofilms formed on the steel counterface were analyzed using an Energy Dispersive X-ray Spectroscopy (SEM-EDX, Energy 350, Oxford) attached to the FE-SEM. In particular, in order to 
gain insight into the formation and function mechanisms of the tribofilms, their structures were characterized using Transmission Electron Microscopy (TEM, Tecnai G2 F20 S-TWIN, FEI) with accelerating voltages of $200 \mathrm{kV}$. Cross-sectional lamellas of tribofilms on the steel counterface were prepared by Focused Ion Beam (FIB) machining in a DualBeam SEM/FIB instrument (Quanta 3D FEG, FEI) with accelerating voltages of $30 \mathrm{kV}$. Prior to FIB machining, the area of interest was coated with a platinum cap layer by ion beam assisted deposition.

\section{Results and Discussion}

\subsection{Friction coefficient and wear rate}

Fig.3 compares the friction coefficients and wear rates when $\mathrm{Bi}_{2} \mathrm{O}_{3} / \mathrm{SCF} / \mathrm{PEEK}$, $\mathrm{CuO} / \mathrm{SCF} / \mathrm{PEEK}, \mathrm{SiO}_{2} / \mathrm{SCF} / \mathrm{PEEK}, \mathrm{ZrO}_{2} / \mathrm{SCF} / \mathrm{PEEK}$ and SCF/PEEK sliding with the steel counterpart. It is manifested that the role of the nanoparticles was dependent on the sliding conditions. At $30 \mathrm{~N}$ and $0.2 \mathrm{~m} / \mathrm{s}(\mathrm{FV}=6 \mathrm{~N} \cdot \mathrm{m} / \mathrm{s})$, the addition of $\mathrm{Bi}_{2} \mathrm{O}_{3}$ or $\mathrm{SiO}_{2}$ nanoparticles into SCF-reinforced PEEK does not change obviously the friction coefficient, whereas the wear resistance is slightly enhanced. However, the addition of $\mathrm{CuO}$ and $\mathrm{ZrO}_{2}$ nanoparticles into SCF/PEEK leads to an obvious increment of both the friction coefficient and wear rate (cf. Fig.3a and b). However, at $30 \mathrm{~N}$ and $1 \mathrm{~m} / \mathrm{s}(\mathrm{FV}=30$ $\mathrm{N} \cdot \mathrm{m} / \mathrm{s}$ ), the addition of $\mathrm{CuO}, \mathrm{SiO}_{2}$ and $\mathrm{ZrO}_{2}$ nanoparticles reduce obviously the friction coefficient of the conventional composite. In particular, $\mathrm{ZrO}_{2} / \mathrm{SCF} / \mathrm{PEEK}$ exhibits the lowest friction coefficient among the composites investigated. The addition of $\mathrm{ZrO}_{2}$ 
nanoparticles does not lead to an obvious change of the wear rate. Nevertheless, the addition of $\mathrm{Bi}_{2} \mathrm{O}_{3}, \mathrm{CuO}$ and $\mathrm{SiO}_{2}$ nanoparticles increases the wear rate.

Under loading conditions higher than $30 \mathrm{~N} \cdot \mathrm{m} / \mathrm{s}$, i.e. 100, 150, 200 and $300 \mathrm{~N} \cdot \mathrm{m} / \mathrm{s}$ (load was varied, whereas speed was fixed at $1 \mathrm{~m} / \mathrm{s}$ ), however, the role of the respective nanoparticles becomes distinct from those under lower loading conditions. As seen from Fig.3, the friction coefficients and wear rates of the composites studied decrease with increasing the $\mathrm{FV}$ factors from 100 to $300 \mathrm{~N} \cdot \mathrm{m} / \mathrm{s}$. In the $\mathrm{FV}$ range concerned, the properties of nanoparticles exert an important influence on the tribological performance. It is demonstrated that further addition of $\mathrm{Bi}_{2} \mathrm{O}_{3}$ nanoparticles into PEEK/SCF leads to an obvious increase of the friction coefficient, whereas further addition of $\mathrm{CuO}$ nanoparticles increases slightly the friction coefficient. However, the two kinds of hard nanoparticles decrease greatly the friction coefficient of the conventional composite. In comparison to $\mathrm{SiO}_{2}$ nanoparticles, $\mathrm{ZrO}_{2}$ nanoparticles are more effective for friction-reduction. $\mathrm{ZrO}_{2} / \mathrm{SCF} / \mathrm{PEEK}$ exhibits friction coefficients even lower than 0.05 at $\mathrm{FV}$ factors higher than $100 \mathrm{~N} \cdot \mathrm{m} / \mathrm{s}$, which is significantly lower than the hybrid nanocomposite containing silica nanoparticles. It is therefore identified that $\mathrm{ZrO}_{2} / \mathrm{SCF} / \mathrm{PEEK}$ has excellent self-lubrication capability especially under severe loading conditions (high FV). From Fig.3a, the self-lubrication performance of the hybrid nanocomposites, following the sequence $\mathrm{ZrO}_{2} / \mathrm{SCF} / \mathrm{PEEK}>\mathrm{SiO}_{2} / \mathrm{SCF} / \mathrm{PEEK}>$ $\mathrm{CuO} / \mathrm{SCF} / \mathrm{PEEK}>\mathrm{Bi}_{2} \mathrm{O}_{3} / \mathrm{SCF} / \mathrm{PEEK}$, shows a close dependence on the hardness the nanoparticles added in the composites. 
Further addition of $\mathrm{Bi}_{2} \mathrm{O}_{3}$ and $\mathrm{CuO}$ nanoparticles into SCF-reinforced PEEK does not change significantly the wear rates under severe loading conditions, i.e. FV values from 100 to $300 \mathrm{~N} \cdot \mathrm{m} / \mathrm{s}$. As consistent with the friction coefficient tendency, the two kinds of hard nanoparticles $\mathrm{SiO}_{2}$ and $\mathrm{ZrO}_{2}$ enhance greatly the wear resistance. Moreover, it is manifested that $\mathrm{ZrO}_{2}$ nanoparticles are more effective for wear-reduction than $\mathrm{SiO}_{2}$ nanoparticles. $\mathrm{ZrO}_{2} / \mathrm{SCF} / \mathrm{PEEK}$ exhibits an ultralow wear rate under severe loading conditions. Taking both the friction and wear characteristics into account, $\mathrm{ZrO}_{2} / \mathrm{SCF} / \mathrm{PEEK}$ exhibits a high tribological performance and thus can be utilized for tribo-engineering components exposed to severe service conditions.

Fig.3c shows the friction coefficient evolutions of the five PEEK composites obtained at $300 \mathrm{~N}$ and $1 \mathrm{~m} / \mathrm{s}(\mathrm{FV}: 300 \mathrm{~N} \cdot \mathrm{m} / \mathrm{s})$. At the starting stage, the friction coefficients of all the composites decrease rapidly following a similar tendency. However, after around $10 \mathrm{~min}$, the friction coefficients of all composites studied increase rapidly. With respect to $\mathrm{Bi}_{2} \mathrm{O}_{3} / \mathrm{SCF} / \mathrm{PEEK}$ and $\mathrm{CuO} / \mathrm{SCF} / \mathrm{PEEK}$, the friction coefficient becomes nearly steady after reaching the maximum value $(0.15-0.20)$. The friction coefficient of SCF/PEEK slightly decreases after it arrives at the highest level. After about 30 min sliding, $\mathrm{SiO}_{2}$ nanoparticles continuously decrease the friction coefficient till the end of the running-in process. It is supposed that when more and more silica nanoparticles are released onto the sliding interface, a lubricating tribofilm is finally formed and leads to friction-reduction [27]. In comparison to $\mathrm{SiO}_{2}$ nanoparticles, $\mathrm{ZrO}_{2}$ nanoparticles reduce the friction coefficient more rapidly, and 
thereby leads to a shorter running-in duration. Moreover, the steady friction coefficient (after running-in) of $\mathrm{ZrO}_{2} / \mathrm{SCF} / \mathrm{PEEK}$ is significantly lower than that of $\mathrm{SiO}_{2} / \mathrm{SCF} / \mathrm{PEEK}$. It is inferred that the running-in duration and the final friction coefficient are related to structure evolution and equilibrium structure of the tribofilm.

\subsection{Tribological mechanisms under low FV condition}

Fig.4 displays the SEM graphs of the worn surfaces of SCF/PEEK, $\mathrm{Bi}_{2} \mathrm{O}_{3} / \mathrm{SCF} / \mathrm{PEEK}$, $\mathrm{CuO} / \mathrm{SCF} / \mathrm{PEEK}$ and $\mathrm{ZrO}_{2} / \mathrm{SCF} / \mathrm{PEEK}$ obtained after sliding at $30 \mathrm{~N}$ and $0.2 \mathrm{~m} / \mathrm{s}(\mathrm{FV}=6$ $\mathrm{N} \cdot \mathrm{m} / \mathrm{s}$ ). As seen from Fig.4a and $\mathrm{b}, \mathrm{SCF}$ protrudes from the worn surfaces of SCF/PEEK and $\mathrm{Bi}_{2} \mathrm{O}_{3} / \mathrm{SCF} / \mathrm{PEEK}$, indicating that $\mathrm{SCF}$ is more abrasion resistant than PEEK matrix. Fiber thinning is deemed to be an important wear mechanism [34]. It seems that the addition of $\mathrm{Bi}_{2} \mathrm{O}_{3}$ nanoparticles does not change significantly the wear mechanism of the conventional composite. Moreover, the worn surfaces are rather smooth with a few ploughing marks parallel to the sliding direction (Fig.4a and b). However, the worn surfaces of $\mathrm{ZrO}_{2} / \mathrm{SCF} / \mathrm{PEEK}$ and $\mathrm{CuO} / \mathrm{SCF} / \mathrm{PEEK}$ show distinctly different morphologies. As seen from Fig.4c and d, numerous deep ploughing grooves are noticed on the worn surfaces of $\mathrm{CuO} / \mathrm{SCF} / \mathrm{PEEK}$ and $\mathrm{ZrO}_{2} / \mathrm{SCF} / \mathrm{PEEK}$. Moreover, it is apparent that the worn surface of the fibers is not as smooth as that on the worn surface of SCF/PEEK.

Fig.5 compares the morphologies of the steel surfaces after sliding with $\mathrm{Bi}_{2} \mathrm{O}_{3} / \mathrm{SCF} / \mathrm{PEEK}$ and $\mathrm{ZrO}_{2} / \mathrm{SCF} / \mathrm{PEEK}$ at $30 \mathrm{~N}$ and $0.2 \mathrm{~m} / \mathrm{s}$. The tribofilm of 
$\mathrm{Bi}_{2} \mathrm{O}_{3} / \mathrm{SCF} / \mathrm{PEEK}$ is very thin and does not cover the whole steel surface. It seems that the tribofilm mainly develops from the initial roughness grooves on the counterface. However, no obvious tribofilm forms on the plateau areas between the roughness grooves. As consistent with our previous observations with conventional composites filled with reinforcing fibers and solid lubricants $[22,27]$, under low FV conditions, compaction of wear particles into the roughness grooves dominates tribofilm formation. With respect to the counterface slid against $\mathrm{ZrO}_{2} / \mathrm{SCF} / \mathrm{PEEK}$, however, large wear particles adhered onto the steel surface and hence a patch-like tribofilm was formed (cf. Fig.5c and d). EDX analyses corroborate that the patch-like tribofilm consists of C-material (from PEEK) and small fraction of $\mathrm{ZrO}_{2}$ nanoparticles. Note that $\mathrm{Au}$ peak in the EDS spectrum derives from the gold coating spurted before SEM inspection for enhancing the electrical conductivity of the polymer surface, as described above. This interpretation also applies to following EDS results. The tribofilm of $\mathrm{CuO} / \mathrm{SCF} / \mathrm{PEEK}$ shows a nearly identical morphology to that of $\mathrm{ZrO}_{2} / \mathrm{SCF} / \mathrm{PEEK}$. During sliding process, scission of $\mathrm{C}-\mathrm{C}$ backbone bond of PEEK can occur. The broken chains can thereafter chelate with the steel and the nanoparticles to form chemical bonding with the steel surface [11, 18]. Bahadur et al. [4] disclosed that $\mathrm{CuO}$ nanoparticles reacted with rubbing steel and enhanced the bonding strength between them. It seems that under low FV conditions, the reinforcing fibers did not scrap away the large particles adhering on the counterface. As a consequence, the compacted large particles led to severe abrasive wear of the polymer composites. It can be therefore inferred that under the low FV 
condition, with the addition of $\mathrm{ZrO}_{2}$ and $\mathrm{CuO}$ nanoparticles, the inferior tribological performance is ascribed to the generation of the patch-like tribofilm.

\subsection{Tribological mechanisms under high FV conditions}

With increasing the FV conditions, the tribological mechanisms become distinctly different and this is true especially for the sliding with FV values larger than $100 \mathrm{~N} \cdot \mathrm{m} / \mathrm{s}$. Fig.6 gives the SEM graphs of the worn surfaces of the five PEEK composites after sliding at $300 \mathrm{~N}$ and $1 \mathrm{~m} / \mathrm{s}$. It is apparent that the worn surfaces are rather smooth. For the hybrid nanocomposites containing $\mathrm{Bi}_{2} \mathrm{O}_{3}, \mathrm{CuO}, \mathrm{SiO}_{2}$ and $\mathrm{ZrO}_{2}$ nanoparticles, $\mathrm{SCF}$ protrudes from the worn surfaces owing to its higher abrasion resistance than the matrix. Moreover, nanoparticles gathered around the protruding fibers (white contrast). During friction process, nanoparticles were released from the wear particles due to degradation of the polymer matrix [22]. Thereafter, the released particles can be retained around the protruding fibers and finally tribo-sintered to a compact piece [22]. It is apparent that the retention of nanoparticles is more significant on the worn surfaces of the hybrid nanocomposites filled with $\mathrm{Bi}_{2} \mathrm{O}_{3}$ nanoparticles probably due to their low melting points, i.e. high element diffusion abilities [29]. In this case, a possible high adhesion between compacted $\mathrm{Bi}_{2} \mathrm{O}_{3}$ and the steel counterface can result in the high friction coefficient.

Fig.7 displays the SEM graphs and EDX analyses of the tribofilms formed on the steel counterface after sliding with $\mathrm{SCF} / \mathrm{PEEK}, \mathrm{CuO} / \mathrm{SCF} / \mathrm{PEEK}, \mathrm{SiO}_{2} / \mathrm{SCF} / \mathrm{PEEK}$ and $\mathrm{ZrO}_{2} / \mathrm{SCF} / \mathrm{PEEK}$ at $\mathrm{FV}=100 \mathrm{~N} \cdot \mathrm{m} / \mathrm{s}$. It is seen from Fig.7a that some wear particles were 
compacted into the roughness grooves. Moreover, direct rubbing between the steel surface and the composite was identified since some initial roughness grooves were polished by the reinforcing fibers. In addition, an obvious tribo-oxidation layer was formed in the direct rubbing areas on the steel surface. Especially under high FV conditions, high flash temperature occurs on the rubbing interface between fiber tips and the steel. Hence, obvious oxidation of the steel occurred [22]. It was demonstrated that direct rubbing with the steel surface and formation of a tribo-oxidation layer result in a high friction coefficient and wear rate of the polymer composite [27].

The addition of soft nanoparticles, i.e. nano- $\mathrm{Bi}_{2} \mathrm{O}_{3}$ and nano- $\mathrm{CuO}$, does not change obviously the tribofilm morphology. As seen from Fig.7b, despite that nano-CuO was compacted with PEEK matrix into roughness grooves on the steel surface, direct steel-composite rubbing and obvious tribo-oxidation of the steel occurred in the plateau areas between the roughness grooves. The authors assume that the tribofilm consisting of PEEK and the soft nanoparticles has a low load-carrying capability, and thus they were mainly retained in the roughness grooves and did not support significant load during the sliding process.

When sliding takes place with $\mathrm{SiO}_{2} / \mathrm{SCF} / \mathrm{PEEK}$, the tribofilm on the counterface does not only distribute in the roughness grooves but also in the plateau areas between these grooves (cf. Fig.7c). It is believed that the tribofilm formed on the plateau areas carries more load than that in the roughness grooves. EDX analyses reveal that the tribofilm contains C-material, silica and tribo-oxidation products, as consistent with our 
characterization results of the tribofilms of hybrid epoxy nanocomposites [22, 27]. Moreover, close inspections of the tribofilm manifest that the tribo-oxidation layer was partly scratched probably by the silica nanoparticles, as indicated by arrow in Fig.7c. When more and more silica nanoparticles are released onto the sliding interface, the formation of tribo-oxidation layer is hindered owing to the three-body abrasion exerted by the abrasive nanoparticles [22, 27]. Finally, nanoparticles, abraded iron oxide and remnant polymer are mixed and tribo-sintered into a compact layer owing to the high flash temperature occurring on fiber tips $[22,27]$. Compared to the softer nanoparticles $\mathrm{Bi}_{2} \mathrm{O}_{3}$ and $\mathrm{CuO}$, silica is more efficient for reducing tribo-oxidation. In addition, the silica-based tribofilm exhibits a higher load carrying capability than those containing $\mathrm{Bi}_{2} \mathrm{O}_{3}$ and $\mathrm{CuO}$. Hence, the silica-based tribofilm alleviates significantly the direct rubbing between the polymer sample and the steel surface. Thus, the tribological performance $\mathrm{SiO}_{2} / \mathrm{SCF} / \mathrm{PEEK}$ exhibits higher tribological performance than

\section{$\mathrm{Bi}_{2} \mathrm{O}_{3} / \mathrm{SCF} / \mathrm{PEEK}$ and $\mathrm{CuO} / \mathrm{SCF} / \mathrm{PEEK}$.}

It seems that release of nano-silica is necessary for getting a highly lubricating tribofilm. The nanostructures of the tribofilms of epoxy-based hybrid nanocomposites formed under various loading conditions were characterized in our recent work [27]. Under a very small FV condition, silica-nanoparticles in the compacted wear particles cannot be released probably owing to the low flash temperature which is not high enough to degrade the polymer matrix. In this case, a C-based tribofilm mainly consisting of polymer matrix and distributing in the roughness grooves was obtained. 
This can be the main reason why the addition of silica nanoparticles does not enhance the tribological performance at $30 \mathrm{~N}$ and $0.2 \mathrm{~m} / \mathrm{s}$.

As described above, $\mathrm{ZrO}_{2} / \mathrm{SCF} / \mathrm{PEEK}$ has the lowest steady friction coefficient and a significantly shorter running-in duration than $\mathrm{SiO}_{2} / \mathrm{SCF} / \mathrm{PEEK}$. As seen from Fig.3c, the friction coefficients of $\mathrm{ZrO}_{2} / \mathrm{SCF} / \mathrm{PEEK}$ and $\mathrm{SiO}_{2} / \mathrm{SCF} / \mathrm{PEEK}$ show a decrease-increase-decrease tendency versus sliding time before arriving at the steady stage. In order to elucidate possible relationship between the running-in tendency and tribofilm structure evolution, tribofilms formed on the steel surface after sliding with $\mathrm{ZrO}_{2} / \mathrm{SCF} / \mathrm{PEEK}$ for 2, 20 and $300 \mathrm{~min}$ (as indicated in Fig.8a) were investigated.

From Fig. $8 \mathrm{~b}$, at the starting stage, a PEEK-based tribofilm is formed on the steel surface slid with $\mathrm{ZrO}_{2} / \mathrm{SCF} / \mathrm{PEEK}$ and this leads to the rapid decrease of the friction coefficient. It is apparent that the tribofilm is uniform and thin, which is different from the patch-like tribofilm obtained at $30 \mathrm{~N}, 0.2 \mathrm{~m} / \mathrm{s}$ (cf. Fig. $5 \mathrm{c}$ and d). Moreover, the PEEK-based tribofilm distribute mainly in the plateau areas between roughness grooves on the steel surface. It is therefore deemed that in this case the tribofilm carries significant load and results in a low friction coefficient.

However, after around 10 min sliding, the friction coefficient stops decreasing and starts to increase due to destruction of the PEEK-based tribofilm. After 20 min sliding, severe oxidation of the steel surface occurs due to direct rubbing of the sliding pair (cf. Fig.8c) and most polymer-based particles retain in the roughness grooves. When the smooth tribo-oxidation layer carries majority of the load, high friction occurs [27]. 
Destruction (removal) of the PEEK-based tribofilm can be caused by tribo-oxidation of the steel, which can reduce the bonding strength of the tribofilm to steel surface. Note that under high FV conditions the decrease-increase tendency of the friction coefficient is independent on the addition of nanoparticles. In this stage, the addition of nanoparticles does not play an important role in the tribological behavior.

With respect to the sliding of $\mathrm{ZrO}_{2} / \mathrm{SCF} / \mathrm{PEEK}$ and $\mathrm{SiO}_{2} / \mathrm{SCF} / \mathrm{PEEK}$, after the friction coefficient reaches the highest value, it starts to decrease again before becoming steady. It is deemed that the decrease of the friction coefficient is related to release of nanoparticles onto the sliding interface. When more and more nanoparticles are released onto the sliding interface, the tribo-oxidation layer can be gradually removed by the abrasive nanoparticles. As seen from Fig.8d, after running-in period, a tribofilm consisting of $\mathrm{ZrO}_{2}$, iron oxide and C-materials are formed on the plateau areas between the roughness grooves, whereas no continuous tribo-oxidation layer is noticeable anymore. Similar to the sliding of the hybrid nanocomposite filled with $\mathrm{SiO}_{2}$, the wear products of released $\mathrm{ZrO}_{2}$ nanoparticles, abraded iron oxide and C-remnant are mixed and finally form a compact layer, as corroborated by TEM analyses of the tribofilm given below. In comparison to nano-silica, $\mathrm{ZrO}_{2}$ nanoparticles are more effective for removing the tribo-oxidation layer due to the higher hardness and thus $\mathrm{ZrO}_{2} / \mathrm{SCF} / \mathrm{PEEK}$ exhibits a shorter running-in process than $\mathrm{SiO}_{2} / \mathrm{SCF} / \mathrm{PEEK}$. From EDX mapping analyses of the worn steel surface, remnant $\mathrm{C}$-material and $\mathrm{ZrO}_{2}$ covers nearly the whole counterface (cf. Fig.8d). It is supposed that the $\mathrm{ZrO}_{2}$-based tribofilm exhibits a 
better load-carrying capability than the $\mathrm{SiO}_{2}$-based tribofilm. Hence, the $\mathrm{ZrO}_{2}$-based tribofilm can mitigate more effectively the direct rubbing of the siding pair, and thereby leads to lower friction and wear.

In order to gain insight into tribofilm's structure of $\mathrm{ZrO}_{2} / \mathrm{SCF} / \mathrm{PEEK}$, FIB-TEM analyses were conducted. Fig.9a gives the TEM graph of cross-section of the tribofilm formed on the steel surface after sliding with $\mathrm{ZrO}_{2} / \mathrm{SCF} / \mathrm{PEEK}$ at $300 \mathrm{~N}$ and $1 \mathrm{~m} / \mathrm{s}$. It is demonstrated that a continuous tribofilm covers the steel surface. Comprehensive characterizations reveal that the tribofilm has a complex structure and mainly consists of four typical regions referred as Zone I, Zone II, Zone III and Zone IV (indicated in Fig.9a). STEM/EDS line analyses indicate that the Zone I (white phase) adjacent to steel surface is mainly composed of amorphous carbon (cf. Fig.9b). This corroborates that at the beginning stage transfer of PEEK-based material dominates tribofilm formation, as observed from Fig.8b. After being subjected to repetitive stressing on the sliding interface, the PEEK material in the tribofilm becomes amorphous. Note that most of transferred PEEK was removed after the running-in process as described above. Unlike the tribofilm of epoxy hybrid nanocomposite containing silica nanoparticles [27], no nano-crystalline iron oxide layer was noticed from Fig.9a and this can give a hint that the tribo-oxidation layer was removed owing to abrasion of hard $\mathrm{ZrO}_{2}$ nanoparticles.

Fig.9c shows the Zone II with a high magnification and it is manifested that this zone consists of $\mathrm{ZrO}_{2}$ with lattice fringes of $0.3165,0.3639$ and $0.5087 \mathrm{~nm}$, 
corresponding respectively to the crystal faces (111), (011), (001) of $\mathrm{ZrO}_{2}$. It is therefore corroborated that released $\mathrm{ZrO}_{2}$ nanoparticles were tribo-sintered to a compact mass in certain areas. Close inspections of Zone III revealed that this zone consists of mixed $\mathrm{ZrO}_{2}$ and $\mathrm{Fe}_{2} \mathrm{O}_{3}$ with lattice spacing of 0.3639 and $0.2700 \mathrm{~nm}$ (cf. Fig.9d), corresponding respectively to the lattice plane (011) of $\mathrm{ZrO}_{2}$ and lattice plane (104) of $\mathrm{Fe}_{2} \mathrm{O}_{3}$. Fig.9e displays high-magnification TEM graph of Zone IV and the corresponding SAED patterns. It is manifested that Zone IV is a mixture of both crystalline and amorphous materials. $\mathrm{ZrO}_{2}$ and $\mathrm{Fe}_{2} \mathrm{O}_{3}$ are identified in this area having lattice planes of (312) and (104), respectively, whereas the amorphous material is attributed to remnant PEEK. It is therefore corroborated that mixing and tribo-sintering of wear products take place during the friction process. In view of the above characterizations, the tribofilm formation is a complex process dominated by various tribo-physical and chemical actions. It can be inferred that the tribofilm were generated following four steps: (i) formation of a C-based film by PEEK transfer; (ii) tribo-oxidation of steel surface after removal of the C-based film; (iii) release of $\mathrm{ZrO}_{2}$ nanoparticles and abrasions on the iron oxide layer; and (iv) mixing and tribo-sintering of wear particles, i.e. nanoparticles, iron oxide and remnant polymer. In step i, the nanoparticles do not significantly influence the tribological behavior. However, in steps ii to iv, the nanoparticles exert an important role in tribofilm formation. The influencing mechanisms of $\mathrm{ZrO}_{2}$ nanoparticles on tribofilm formation are schematically illustrated in Fig.10 (steps ii, iii and iv). The authors believe that hard nanoparticles are more 
effective for removing the iron oxide layer and therefore lead to a shorter running-in duration. Moreover, it seems that the tribofilms containing hard nanoparticles has a higher load-carrying capability and therefore enhances more effectively the tribological performance of the conventional composite.

\section{Conclusions}

In the present work, various kinds of oxide nanoparticles i.e. $\mathrm{Bi}_{2} \mathrm{O}_{3}, \mathrm{CuO}, \mathrm{SiO}_{2}$ and $\mathrm{ZrO}_{2}$ with distinct hardness and melting point were added into a PEEK conventional composite reinforced with SCF. The effect of nanoparticle types on the tribological behavior and tribofilm formation of the PEEK composite was comprehensively investigated. Following conclusions were obtained:

(1) Nanoparticle types play an important role in the tribological performance of the PEEK composite. When sliding at low FV condition, the addition of $\mathrm{CuO}$ and $\mathrm{ZrO}_{2}$ nanoparticles leads to obviously increased friction and wear. At FV conditions higher than $30 \mathrm{~N} \cdot \mathrm{m} / \mathrm{s}$, the addition of $\mathrm{Bi}_{2} \mathrm{O}_{3}$ and $\mathrm{CuO}$ nanoparticles does not lead to a positive role in the tribological performance. However, the addition of $\mathrm{SiO}_{2}$ and $\mathrm{ZrO}_{2}$ nanoparticles decreases dramatically the friction coefficient and wear rate at FV factors higher than $30 \mathrm{~N} \cdot \mathrm{m} / \mathrm{s}$. Especially under high $\mathrm{FV}$ conditions, $\mathrm{ZrO}_{2}$ nanoparticles are more effective than $\mathrm{SiO}_{2}$ nanoparticles in regards to friction- and wear-reduction. It is deemed that the tribological mechanisms of the nanoparticles are closely dependent on their hardness. 
(2) Nanoparticle types are of great importance for tribofilm structures. When sliding at $6 \mathrm{~N} \cdot \mathrm{m} / \mathrm{s}$, the addition of $\mathrm{CuO}$ and $\mathrm{ZrO}_{2}$ nanoparticles led to the formation of a patch-like tribofilm, and thereby high friction and wear rate were obtained. However, at FV conditions higher than $30 \mathrm{~N} \cdot \mathrm{m} / \mathrm{s}$, the hard nanoparticles i.e. $\mathrm{SiO}_{2}$ and $\mathrm{ZrO}_{2}$, released onto the sliding interface can play a polishing effect and removed the oxidation layer on the steel counterface. Hereafter, the hard nanoparticles were mixed with remnant polymer particles and tribo-oxidation products, and were finally "tribo-sintered" into a ceramic-based compact tribofilm. It seemed that such tribofilms showed a high load-carrying capability and therefore mitigated the direct rubbing between the sliding pairs. In comparison to nano- $\mathrm{SiO}_{2}, \mathrm{ZrO}_{2}$ nanoparticles removed more effectively the oxidation layer. Moreover, it seemed that the $\mathrm{ZrO}_{2}$-based tribofilm exhibited a higher load-carrying capability than the $\mathrm{SiO}_{2}$-based one, and hence played a better friction- and wear-reduction role. However, the addition of soft nanoparticles, i.e. $\mathrm{Bi}_{2} \mathrm{O}_{3}$ and $\mathrm{CuO}$, into the conventional composite did not help to form a robust and lubricating tribofilm.

(3) Inclusion of hard nanoparticles into SCF-reinforced PEEK composites was identified to be an effective route for developing tribo-composites subjected to severe FV conditions. It is speculated that the volume fraction of the hard nanoparticles and the interfacial bonding between the matrix and the hard particle can exert an important role in the release speed of nanoparticles, and thereby can affect the running-in duration. Thus, it can be of interest to tailor composites with short running-in duration by optimizing nanoparticles' fraction and their interface with the polymer matrix. 
Moreover, as identified by previous works, tribo-chemical reactions of polymer molecules, e.g. PPS and PTFE, with the steel counterpart readily occurred. In this case, tribofilm formation would become more complex and the nanoparticles can play a distinct role from those in the PEEK-based system. Efforts will be dedicated to the above aspects in our following work, in order to deepen understanding on the tribological mechanisms of polymer hybrid nanocomposites.

\section{Acknowledgments}

The authors acknowledge gratefully the financial support from National Science Foundation of China (Grant no. 51475446) and the Chinese "Thousand Youth Talents Plan" Project.

\section{References}

[1] Gao J, Mao S, Liu J, Feng D. Tribochemical effects of some polymers/stainless steel. Wear. $1997 ; 212(2): 238-43$.

[2] Ramachandra S, Ovaert T. The effect of controlled surface topographical features on the unlubricated transfer and wear of PEEK. Wear. 1997;206(1):94-9.

[3] Gao J. Tribochemical effects in formation of polymer transfer film. Wear. 2000;245(1):100-6.

[4] Bahadur S, Gong D, Anderegg J. The role of copper compounds as fillers in transfer film formation and wear of nylon. Wear. 1992;154(2):207-23.

[5] Bahadur S, Kapoor A. The effect of $\mathrm{ZnF} 2, \mathrm{ZnS}$ and $\mathrm{PbS}$ fillers on the tribological behavior of nylon 
11. Wear. 1992;155(1):49-61.

[6] Wang Q, Xue Q, Liu H, Shen W, Xu J. The effect of particle size of nanometer $\mathrm{ZrO}_{2}$ on the tribological behaviour of PEEK. Wear. 1996;198(1):216-9.

[7] Wang Q, Xue Q, Shen W. The friction and wear properties of nanometre $\mathrm{SiO}_{2}$ filled polyetheretherketone. Tribol Int. 1997;30(3):193-7.

[8] Bijwe J, Indumathi J. Influence of fibers and solid lubricants on low amplitude oscillating wear of polyetherimide composites. Wear. 2004;257(5):562-72.

[9] Gong D, Xue Q, Wang H. ESCA study on tribochemical characteristics of filled PTFE. Wear. 1991;148(1):161-9.

[10] Zhang Z, Breidt C, Chang L, Haupert F, Friedrich K. Enhancement of the wear resistance of epoxy: short carbon fibre, graphite, PTFE and nano- $\mathrm{TiO}_{2}$. Composites Part A. 2004;35(12):1385-92.

[11] Harris KL, Pitenis AA, Sawyer WG, Krick BA, Blackman GS, Kasprzak DJ, et al. PTFE tribology and the role of mechanochemistry in the development of protective surface films. Macromolecules. 2015;48(11):3739-45.

[12] Xue Q, Wang Q. Wear mechanisms of polyetheretherketone composites filled with various kinds of SiC. Wear. 1997;213(1):54-8.

[13] He J, Zhang L, Li C. Thermal conductivity and tribological properties of POM-Cu composites. Polym Eng Sci. 2010;50(11):2153-9.

[14] Sharma S, Bijwe J, Panier S, Sharma M. Abrasive wear performance of SiC-UHMWPE nano-composites-Influence of amount and size. Wear. 2015;332:863-71.

[15] Zhang G, Schlarb A, Tria S, Elkedim O. Tensile and tribological behaviors of PEEK/nano-SiO 
composites compounded using a ball milling technique. Compos Sci Technol. 2008;68(15):3073-80.

[16] Bahadur S, Sunkara C. Effect of transfer film structure, composition and bonding on the tribological behavior of polyphenylene sulfide filled with nano particles of $\mathrm{TiO}_{2}, \mathrm{ZnO}, \mathrm{CuO}$ and $\mathrm{SiC}$. Wear. 2005;258(9):1411-21.

[17] Beckford S, Mathurin L, Chen J, Zou M. The Influence of Cu Nanoparticles on the Tribological Properties of Polydopamine/PTFE+ Cu Films. Tribol Lett. 2015;59(1):1-9.

[18] Pitenis AA, Harris KL, Junk CP, Blackman GS, Sawyer WG, Krick BA. Ultralow wear PTFE and alumina composites: it is all about tribochemistry. Tribol Lett. 2015;57(1):1-8.

[19] Shen J, Top M, Pei Y, De Hosson JTM. Wear and friction performance of PTFE filled epoxy composites with a high concentration of $\mathrm{SiO}_{2}$ particles. Wear. 2015;322:171-80.

[20] Wang Q, Zhang X, Pei X. Study on the synergistic effect of carbon fiber and graphite and nanoparticle on the friction and wear behavior of polyimide composites. Mater Des. 2010;31(8):3761-8.

[21] Zhang G, Sebastian R, Burkhart T, Friedrich K. Role of monodispersed nanoparticles on the tribological behavior of conventional epoxy composites filled with carbon fibers and graphite lubricants.

Wear. 2012;292:176-87.

[22] Zhang G, Wetzel B, Jim B, Österle W. Impact of counterface topography on the formation mechanisms of nanostructured tribofilm of PEEK hybrid nanocomposites. Tribol Int. 2015;83:156-65.

[23] Friedrich K, Zhang Z, Schlarb AK. Effects of various fillers on the sliding wear of polymer composites. Compos Sci Technol. 2005;65(15):2329-43.

[24] Österle W, Dmitriev A, Gradt T, Häusler I, Hammouri B, Guzman PM, et al. Exploring the beneficial role of tribofilms formed from an epoxy-based hybrid nanocomposite. Tribol Int. 2015;88:126-34. 
[25] Chang L, Zhang Z, Breidt C, Friedrich K. Tribological properties of epoxy nanocomposites. Wear. $2005 ; 258(1-4): 141-8$.

[26] Chang L, Zhang Z. Tribological properties of epoxy nanocomposites. Wear. 2006;260(7-8):869-78.

[27] Zhang G, Häusler I, Österle W, Wetzel B, Jim B. Formation and function mechanisms of nanostructured tribofilms of epoxy-based hybrid nanocomposites. Wear. 2015;342:181-8.

[28] Alves S, Mello V, Faria E, Camargo A. Nanolubricants developed from tiny CuO nanoparticles. Tribol Int. 2016.

[29] Kato H, Komai K. Tribofilm formation and mild wear by tribo-sintering of nanometer-sized oxide particles on rubbing steel surfaces. Wear. 2007;262(1):36-41.

[30] Sharma M, Bijwe J, Mitschang P. Wear performance of PEEK-carbon fabric composites with strengthened fiber-matrix interface. Wear. 2011;271(9):2261-8.

[31] Flöck J, Friedrich K, Yuan Q. On the friction and wear behaviour of PAN- and pitch-carbon fiber reinforced PEEK composites. Wear 1999;225-229:304-11.

[32] Friedrich K, Lu Z, Hager AM. Recent advances in polymer composites' tribology. Wear. 1995; 190:139-44.

[33] Zhang G. Structure-tribological property relationship of nanoparticles and short carbon fibers reinforced PEEK hybrid composites. Journal of Polymer Science Part B: Polymer Physics. 2010;48(7):801-11.

[34] Friedrich K. Wear of reinforced polymers by different abrasive counterparts. Friction and wear of polymer composites. 1986;1:233-87.

[35] Zyryanov V, Smirnov V, Ivanovskaya M. Mechanochemical synthesis of crystalline compounds in 
the $\mathrm{Bi}_{2} \mathrm{O}_{3}-\mathrm{GeO}_{2}$ system. Inorg Mater. 2005;41(6):618-26.

[36] Singh RK, Gainesville SM, chemical-mechanical polishing slurry for polishing of copper or silver films, United States Patent Application Publication, US20030159362A1, 2003

[37] Davraz M, Gunduz L. Engineering properties of amorphous silica as a new natural pozzolan for use in concrete. Cem Concr Res. 2005;35(7):1251-61.

[38] Düvel A, Romanova E, Sharifi M, Freude D, Wark M, Heitjans P, et al. Mechanically Induced Phase Transformation of $\gamma-\mathrm{Al}_{2} \mathrm{O}_{3}$ into $\alpha-\mathrm{Al}_{2} \mathrm{O}_{3}$. Access to Structurally Disordered $\gamma-\mathrm{Al}_{2} \mathrm{O}_{3}$ with a Controllable Amount of Pentacoordinated Al Sites. J Phys Chem C. 2011;115(46):22770-80. 

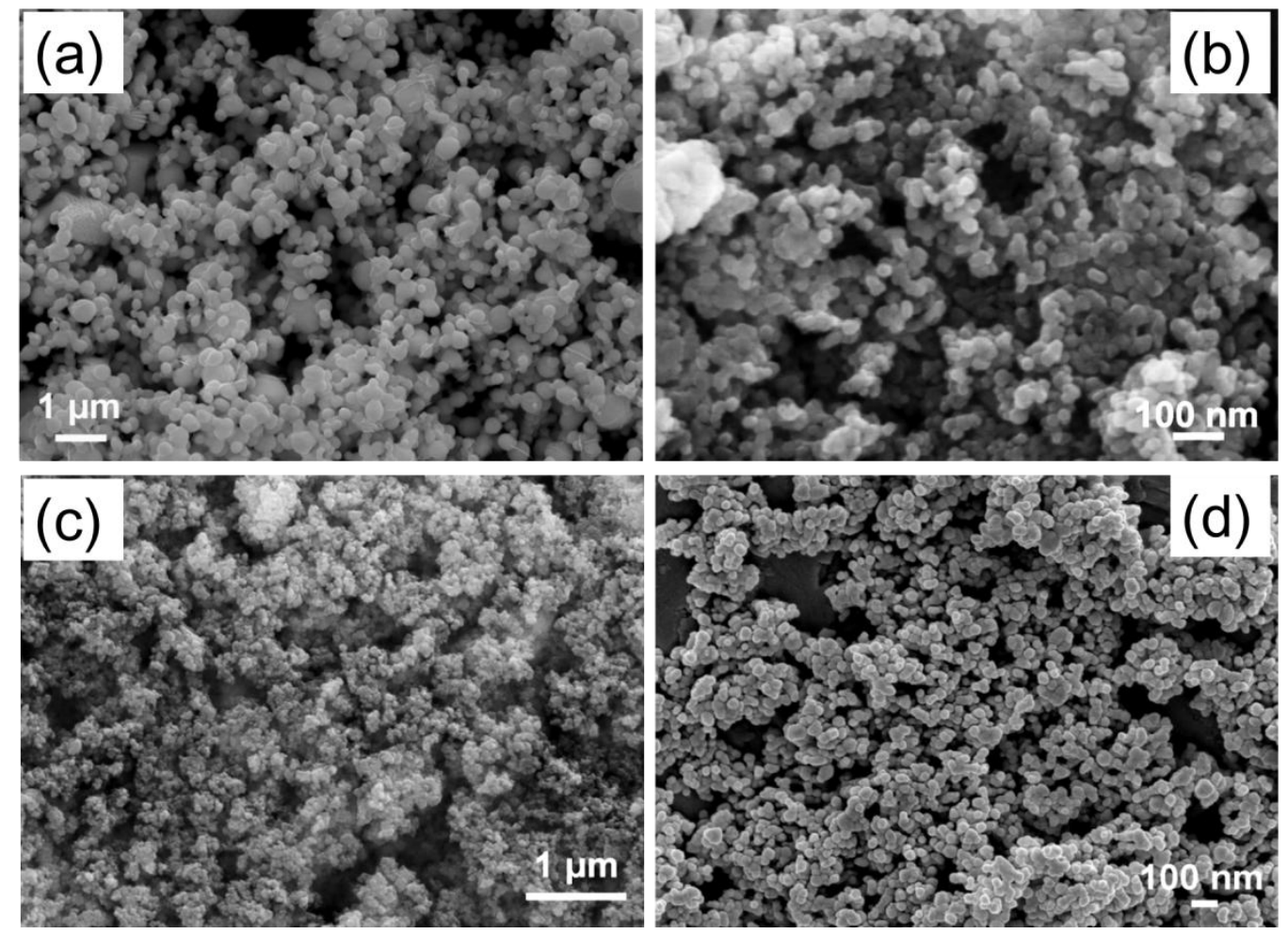

Fig.1. SEM morphologies of (a) $\mathrm{Bi}_{2} \mathrm{O}_{3}$, (b) $\mathrm{CuO}$, (c) $\mathrm{SiO}_{2}$, (d) $\mathrm{ZrO}_{2}$ nanoparticles.

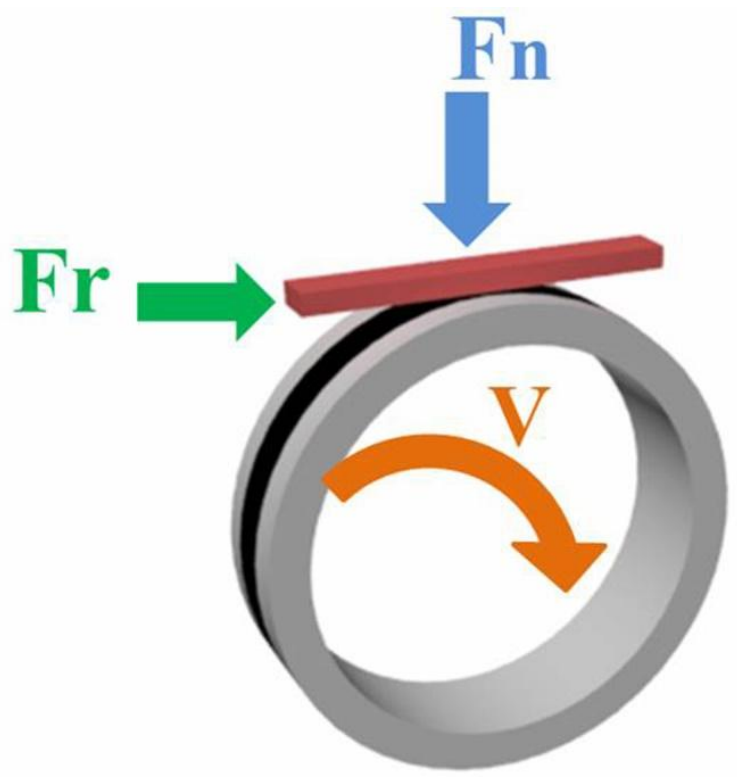

Fig.2. Schematic diagram of contact configuration of the friction pairs. 

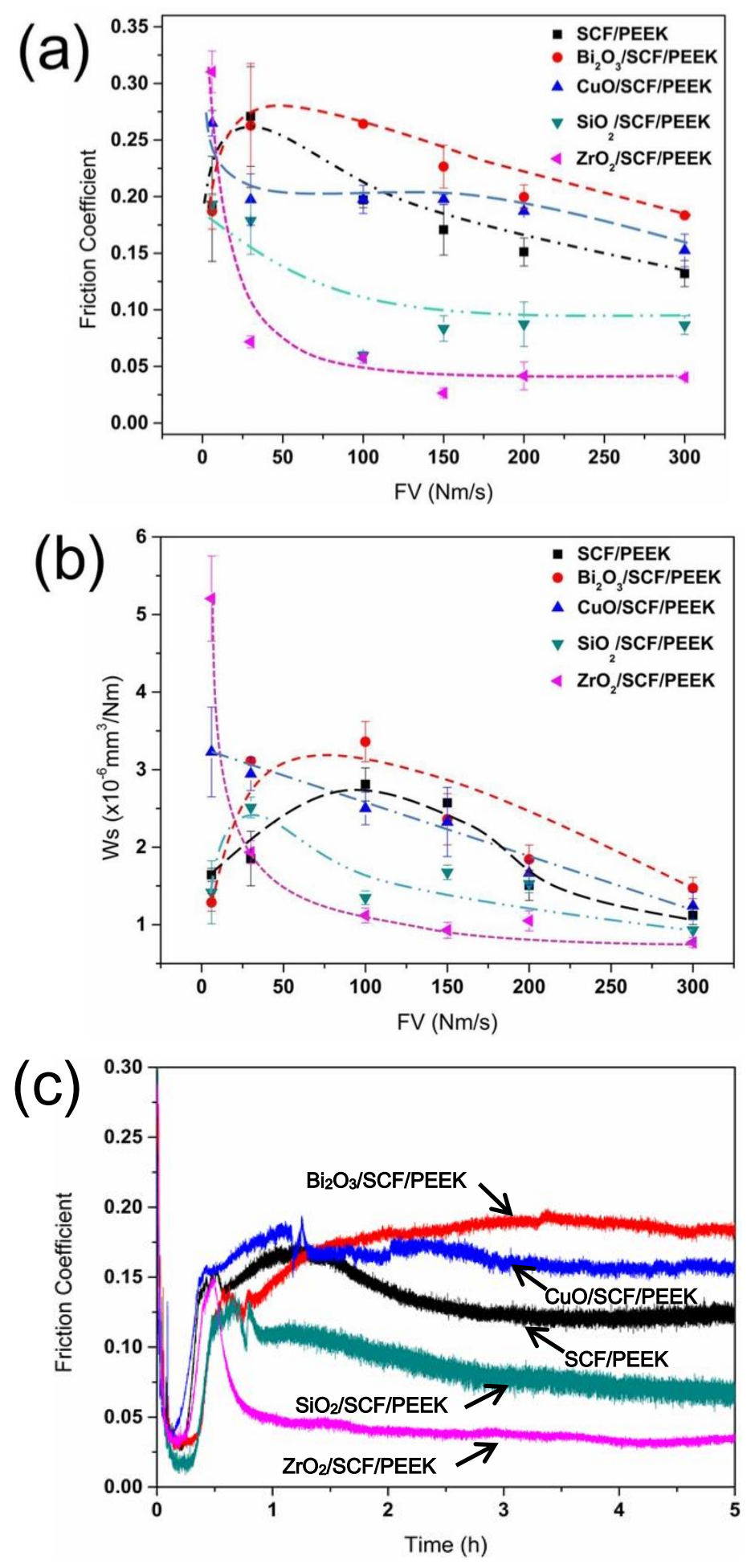

Fig.3. Effect of various nanoparticles on (a) mean friction coefficients and (b) wear rates of SCF-reinforced PEEK obtained under different FV conditions; (c) friction coefficient evolutions of the PEEK composites versus sliding time obtained at $300 \mathrm{~N}$ and $1 \mathrm{~m} / \mathrm{s}$. 


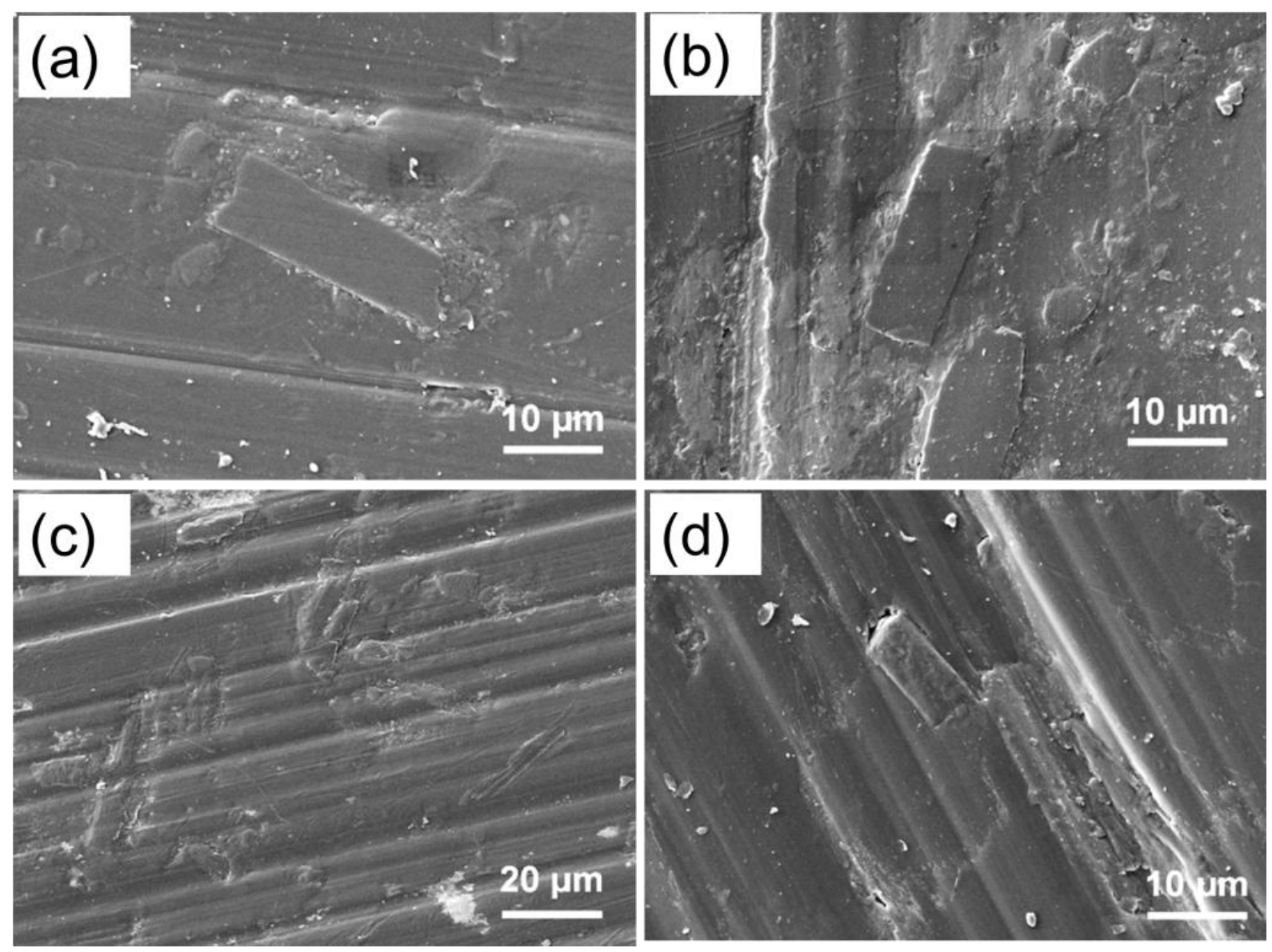

Fig.4. SEM graphs of the worn surfaces of SCF/PEEK (a), $\mathrm{Bi}_{2} \mathrm{O}_{3} / \mathrm{SCF} / \mathrm{PEEK}$ (b), $\mathrm{CuO} / \mathrm{SCF} / \mathrm{PEEK}$ (c) and $\mathrm{ZrO}_{2} / \mathrm{SCF} / \mathrm{PEEK}$ (d). Sliding speed: $0.2 \mathrm{~m} / \mathrm{s}$, normal force: 30 N. 

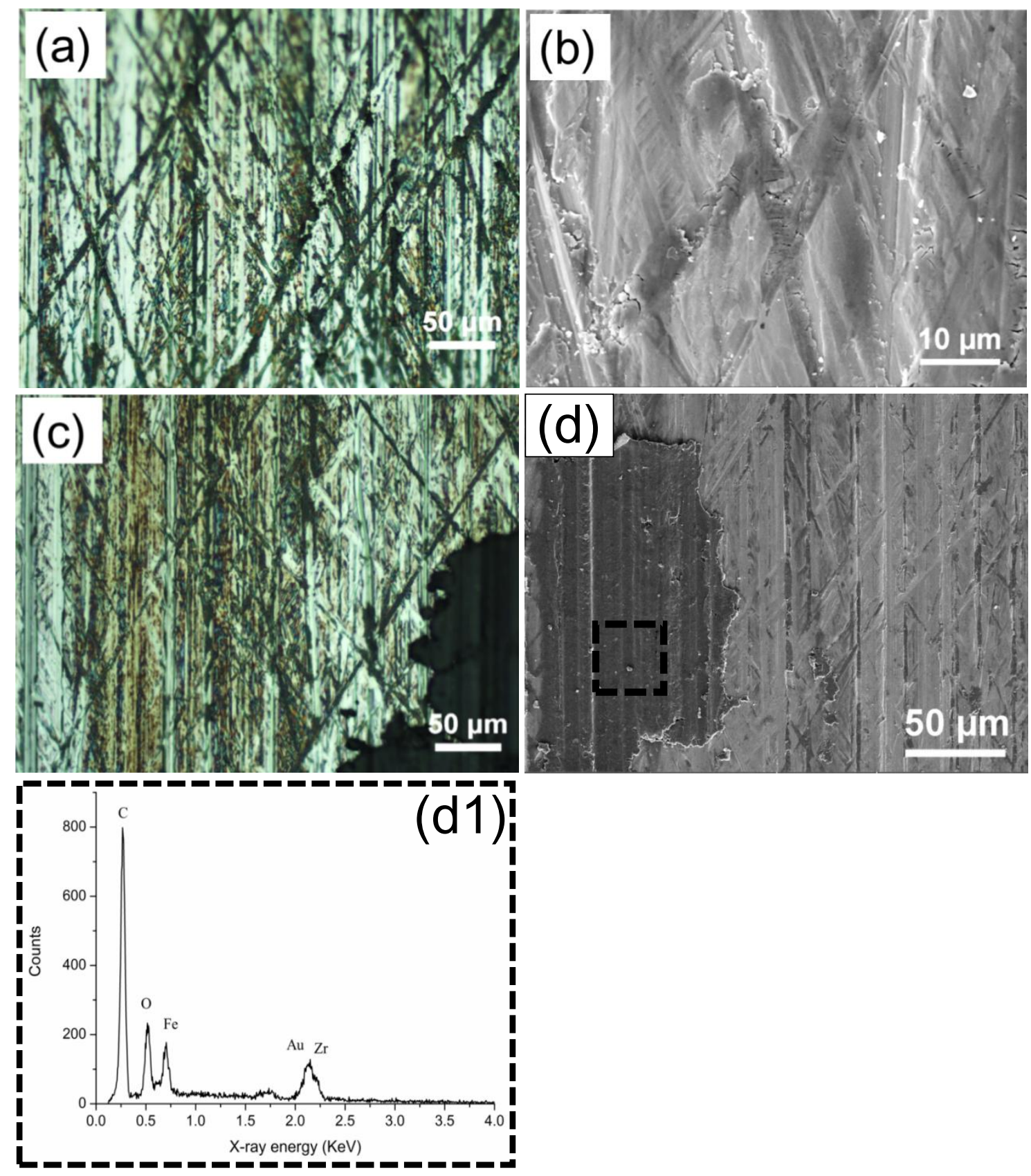

Fig.5. Optical micrographs (a, c) and SEM (b, d) images of tribofilms formed on GCr15 counterface after sliding against $\mathrm{Bi}_{2} \mathrm{O}_{3} / \mathrm{SCF} / \mathrm{PEEK}(\mathrm{a}, \mathrm{b})$ and $\mathrm{ZrO}_{2} / \mathrm{SCF} / \mathrm{PEEK}(\mathrm{c}, \mathrm{d})$ at $0.2 \mathrm{~m} / \mathrm{s}$ and $30 \mathrm{~N} ;(\mathrm{d} 1)$ EDX analyses of the area indicated in the rectangle in $\mathrm{d}$. 

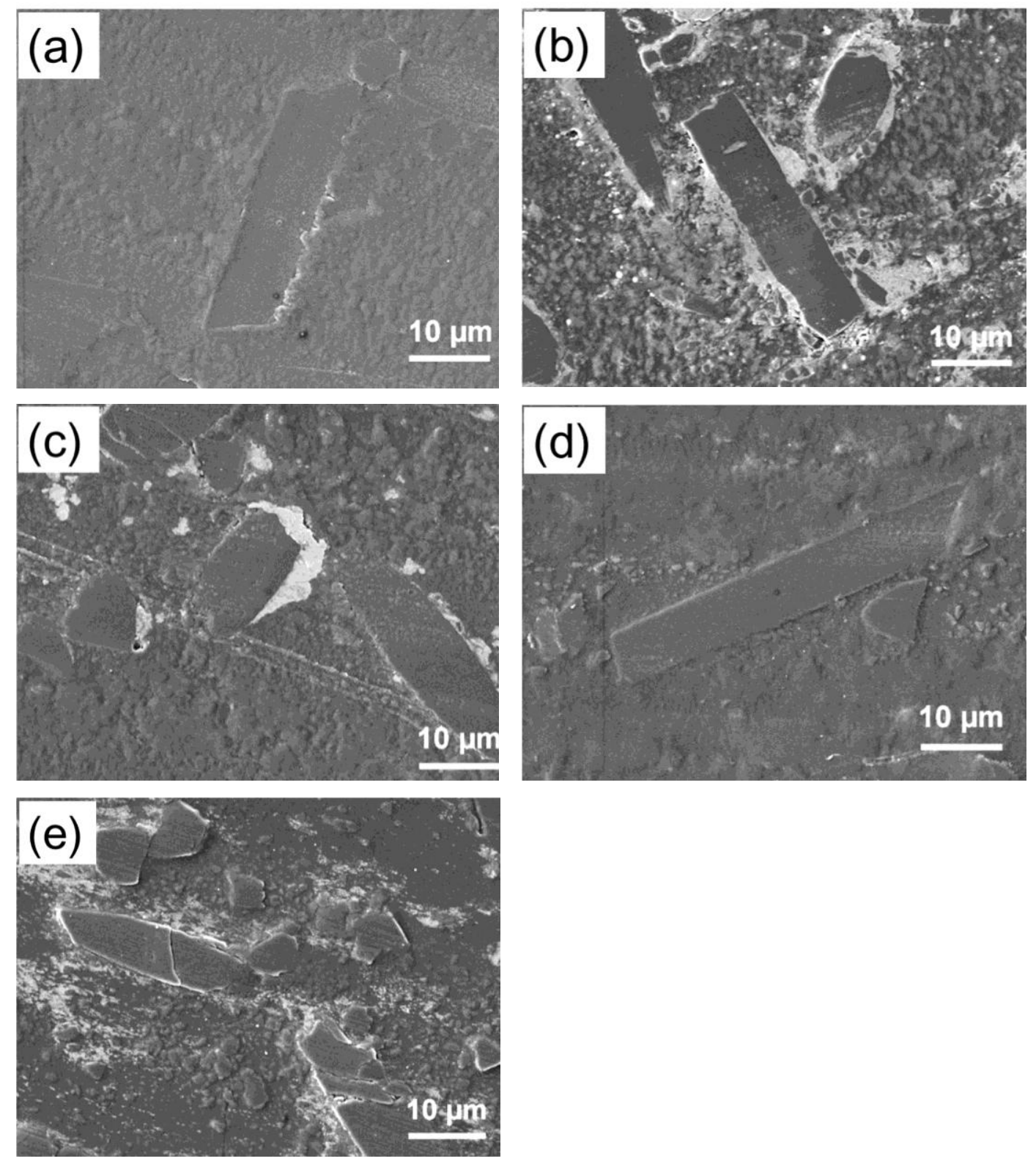

Fig.6. SEM graphs of the worn surface of (a) SCF/PEEK, (b) $\mathrm{Bi}_{2} \mathrm{O}_{3} / \mathrm{SCF} / \mathrm{PEEK}$, (c) $\mathrm{CuO} / \mathrm{SCF} / \mathrm{PEEK}$, (d) $\mathrm{SiO}_{2} / \mathrm{SCF} / \mathrm{PEEK}$ and (e) $\mathrm{ZrO}_{2} / \mathrm{SCF} / \mathrm{PEEK}$ obtained at $300 \mathrm{~N}$ and $1 \mathrm{~m} / \mathrm{s}$. 


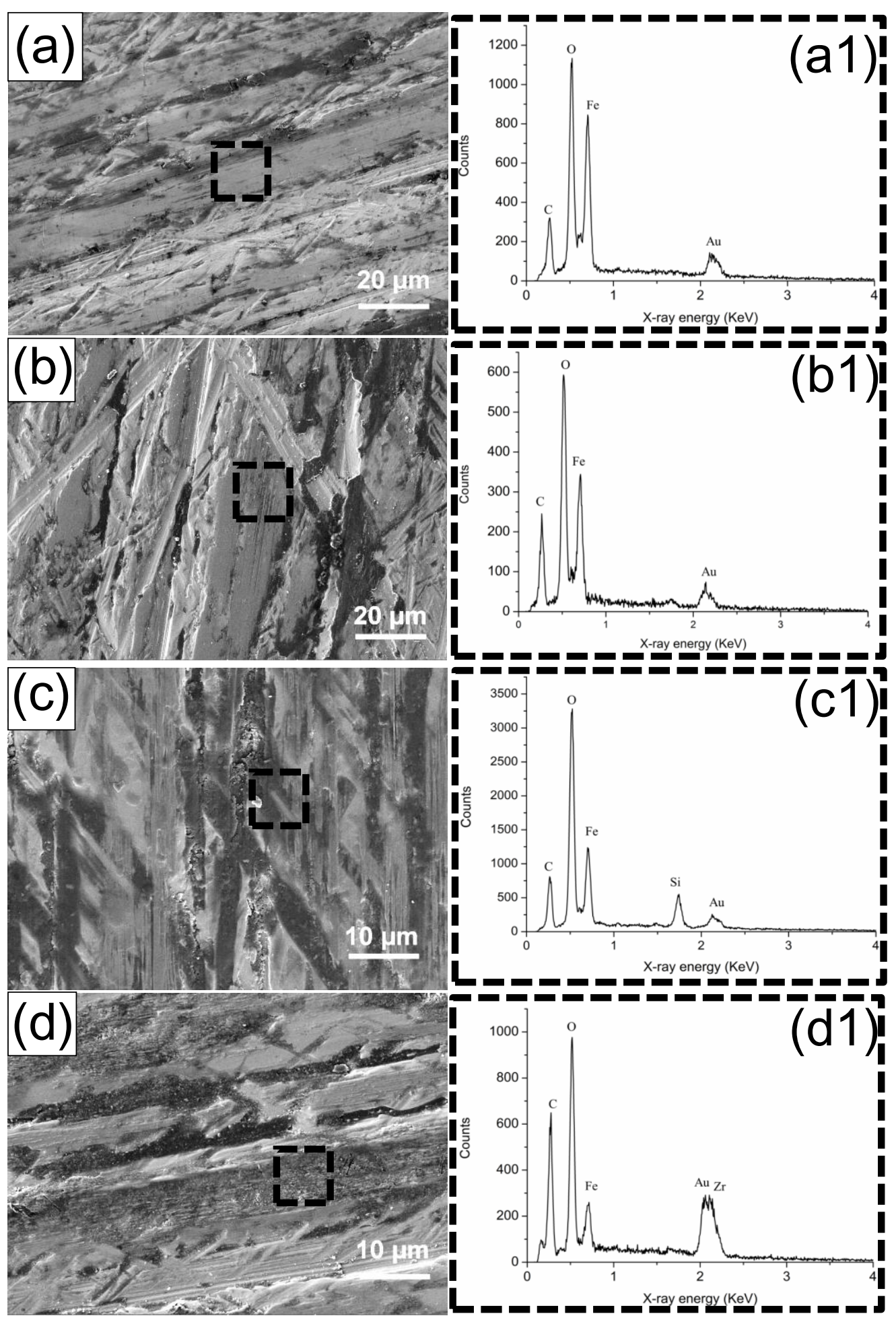

Fig.7. SEM graphs (a, b, c, d) and EDX spectra (a1, b1, c1, d1) of tribofilms formed on the steel surface after sliding against (a) SCF/PEEK, (b) $\mathrm{CuO} / \mathrm{SCF} / \mathrm{PEEK}$, (c) $\mathrm{SiO}_{2} / \mathrm{SCF} / \mathrm{PEEK}$ and (d) $\mathrm{ZrO}_{2} / \mathrm{SCF} / \mathrm{PEEK}$ at $100 \mathrm{~N}$ and $1 \mathrm{~m} / \mathrm{s}$. 

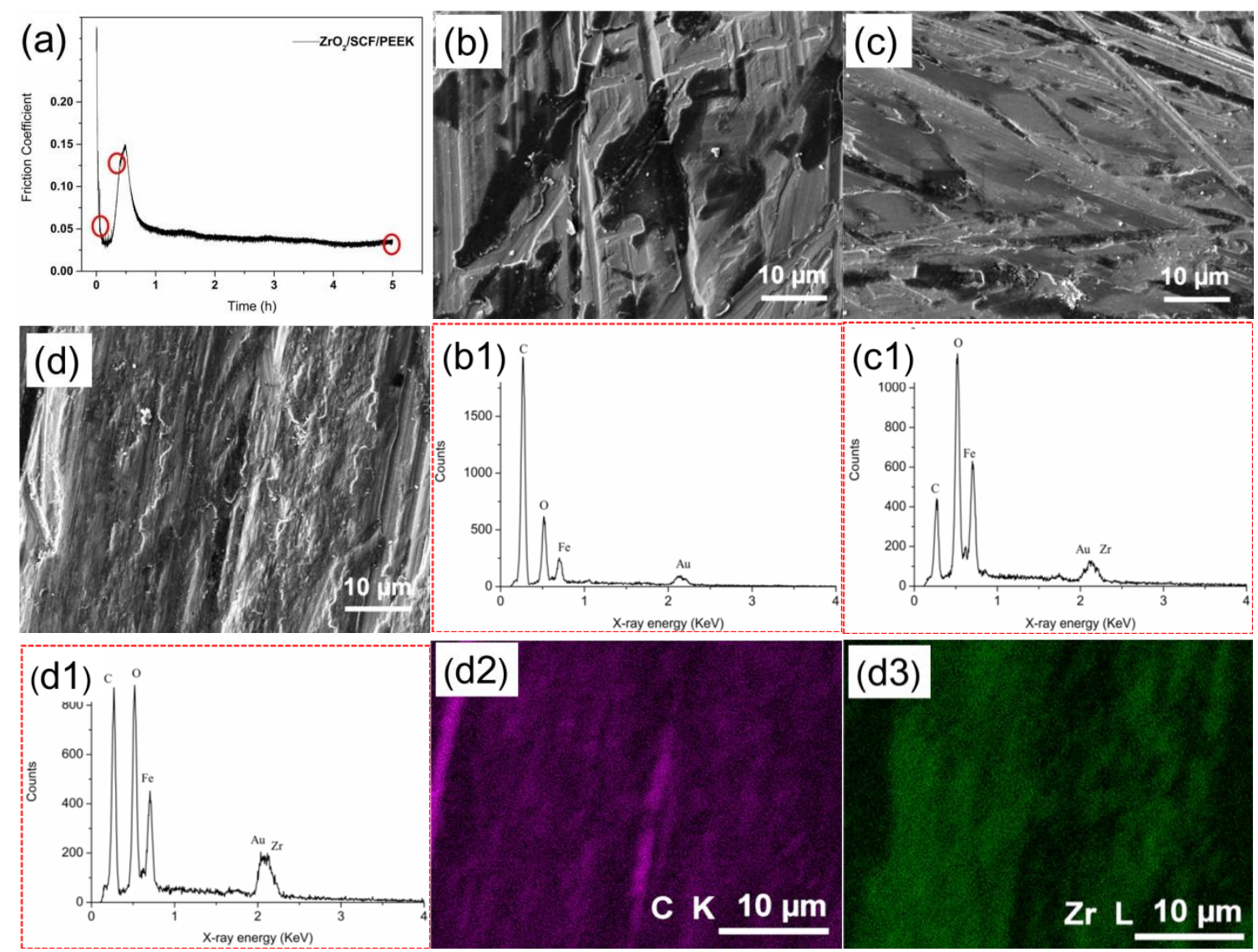

(d3)

Fig.8. (a) Friction coefficient evolutions of $\mathrm{ZrO}_{2} / \mathrm{SCF} / \mathrm{PEEK}$ versus sliding time; SEM graphs and EDX spectra of tribofilms formed on GCr15 counterface after sliding for 2 $\min (b, b 1), 20 \min (c, c 1), 300 \min (d, d 1, d 2$, d3). Normal force: 300N, sliding speed: $1 \mathrm{~m} / \mathrm{s}$. 

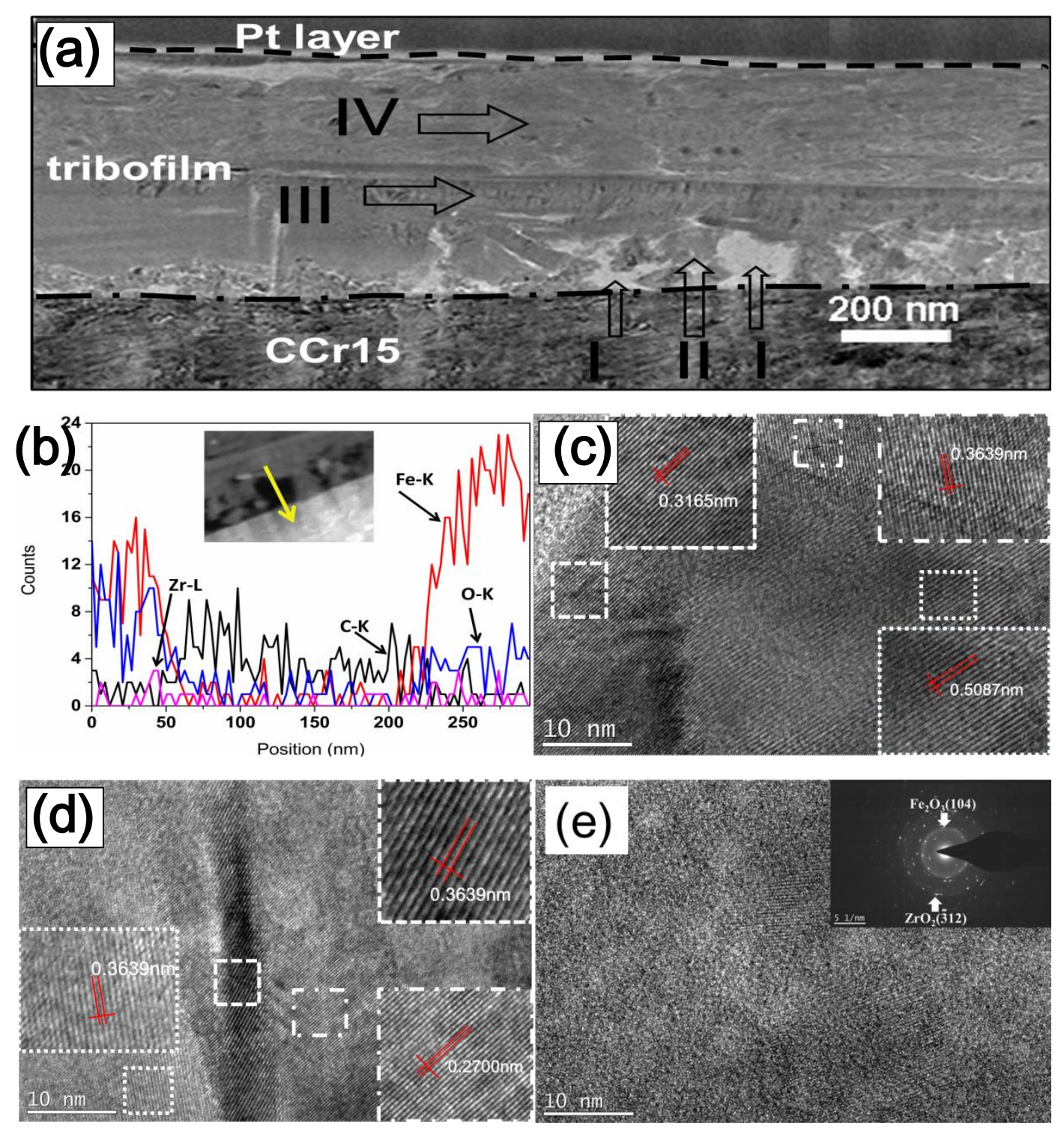

Fig.9. (a) TEM graph of tribofilm's cross-section formed on the steel surface after sliding against $\mathrm{ZrO}_{2} / \mathrm{SCF} / \mathrm{PEEK}$ at $1 \mathrm{~m} / \mathrm{s}$ and $300 \mathrm{~N}$; (b) EDX line scans across the Zone I; (c) high-magnification TEM graphs of zone II; (d) high-magnification TEM graphs of zone III; (e) high-magnification TEM graph of zone IV with an inset showing the corresponding SAED patterns. 


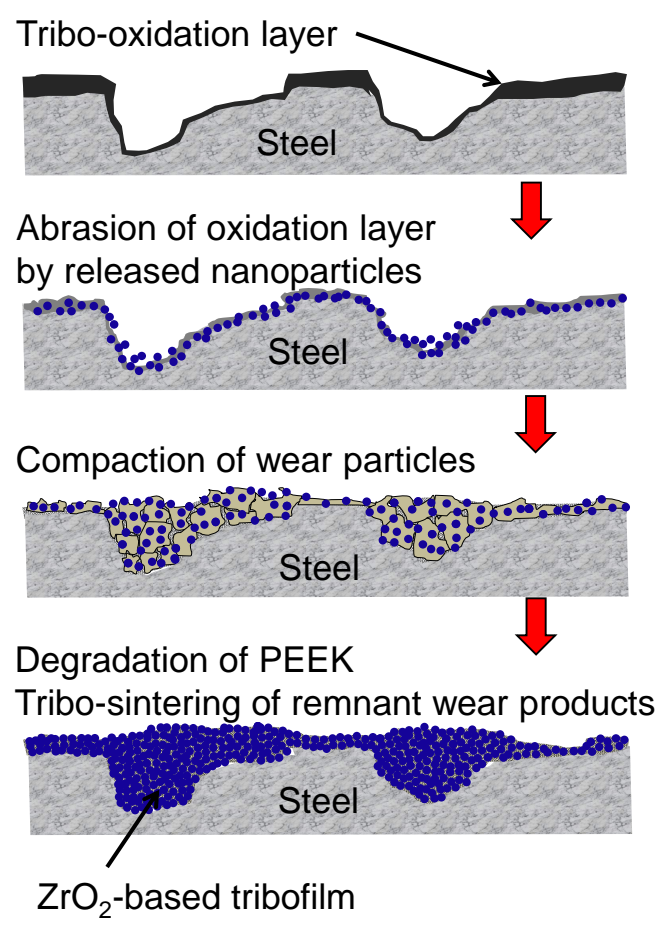

Fig. 10. Schematic illustration of effect of $\mathrm{ZrO}_{2}$ nanoparticles on tribofilm formation. The final tribofilm contains $\mathrm{ZrO}_{2}$, remnant PEEK and abraded iron oxide. Blue dots represent $\mathrm{ZrO}_{2}$ nanoparticles. 
Table.1. Diameters and physical parameters of oxide particles

\begin{tabular}{cccc}
\hline Nanoparticles & Diameter $(\mathrm{nm})$ & Melting point $\left({ }^{\circ} \mathrm{C}\right)$ & Moh's hardness \\
\hline $\mathrm{Bi}_{2} \mathrm{O}_{3}$ & $80-200$ & 824 & $4.5[35]$ \\
$\mathrm{CuO}$ & 30 & 1326 & $3-4[36]$ \\
$\mathrm{SiO}_{2}$ & 20 & $1650( \pm 50)$ & $7[37]$ \\
$\mathrm{ZrO}_{2}$ & 30 & 2700 & $8-9[38]$ \\
\hline
\end{tabular}

